\title{
Visual arts in counselling adults with depressive disorders
}

\author{
Khai Ling Lee ${ }^{a}$, M.S. Mustaffa ${ }^{b}$ and S.Y. $\operatorname{Tan}^{c}$ \\ ${ }^{a}$ Faculty of Education, Universiti Teknologi Malaysia, Johor, Malaysia; ${ }^{b}$ Faculty of Cognitive Sciences and Human \\ Development, Universiti Malaysia Sarawak, Sarawak, Malaysia; ${ }^{C}$ National Institute of Education, Nanyang \\ Technological University, Singapore
}

\begin{abstract}
This study provides a better understanding of using visual arts in counselling adults with depressive disorders. Three in-depth case studies were conducted in the counselling unit of a mental health hospital in Malaysia. Both qualitative and quantitative research methods were applied to explore three adult participants' counselling experiences. They attended six individual counselling sessions, which included four art-making activities, and two after-session interviews, for approximately two months. Interpretative Phenomenological Analysis was used to analyse the qualitative data. The findings showed that through the therapeutic use of visual arts, the participants were able to explore and express various emotions, face their problems, communicate better with themselves and the counsellor, achieve a deeper self-understanding, and make meaningful progress in counselling, even though some of them experienced a sense of uncertainty at the beginning of some art-making activities.
\end{abstract}

\section{ARTICLE HISTORY}

Received 2 June 2014

Revised 25 August 2015

Accepted 25 November 2015

\section{KEYWORDS}

Counselling; depressive disorders; visual arts

\section{Introduction}

Recently the benefits of using visual arts in counselling have been reported by some practitioners and researchers (Gladding, 2011; Gladding \& Newsome, 2003; Kahn, 1999). The meaning of visual arts are defined as the activities and products of drawing, painting, and sculpturing, rather than literature and music in the Cambridge Advanced Learner's Dictionary (2003). In the counselling setting, visual arts can help clients to obtain information from their unconscious minds, express their covert conflicts and chaotic emotions, picture themselves or their situation realistically, reveal their problems that are difficult to talk about, understand their inner self, and communicate with their counsellor (Gladding, 2011; Gladding \& Newsome, 2003). When Kahn (1999) used a step-by-strep art approach in counselling an adolescent with substance abuse, the researcher found that the art approach was less threatening than the traditional therapeutic interventions for helping adolescents in school.

Faiver, Eisengart, and Colonna (2004) described art approach as a powerful therapeutic tool for clients who have difficulty in verbal expression. They pointed out that both clients and their counsellors, including trainee counsellors, do not need to have special talents in using art as an alternative communication tool to help their clients in counselling sessions. However, practitioners suggested that counsellors should select art-making activities and directives carefully because these activities should be consistent with their client's needs and goals at each counselling stage (Gladding \& Newsome, 2003; Kahn, 1999). Besides, counsellors should know that not every client will enjoy doing art, and sometimes it may take several sessions for a client to actually begin enjoying and benefiting from art experiences (Gladding, 2011). 